Check for updates

Cite this: RSC Adv., 2017, 7, 21164

Received 22nd January 2017

Accepted 3rd April 2017

DOI: $10.1039 / \mathrm{c} 7 \mathrm{ra00952f}$

rsc.li/rsc-advances

\title{
Ultrasensitive hydrazine sensor fabrication based on Co-doped ZSM-5 zeolites for environmental safety $\uparrow$
}

\begin{abstract}
Mohammed M. Rahman, (D) * Bahaa M. Abu-Zied and Abdullah M. Asiri (iD
Various Co-loaded ZSM-5 zeolites (Co-ZSM-5) were prepared and the details of their structural, morphological and elemental properties characterized by different conventional methods. A flat glassy carbon electrode (GCE) was modified with the Co-ZSM-5 (150\%-loading) materials to obtain a sensor for hydrazine (Hyd) which displays improved sensitivity, a large dynamic range and good long-term stability. The calibration plot (best acquired at a voltage of $+0.4 \mathrm{~V})$ is linear $\left(r^{2}=0.9968\right)$ in the $0.01 \mathrm{nM}$ to $0.01 \mathrm{mM}$ Hyd concentration range. The detection limit is as low as $9.1 \mathrm{pM}$, and the sensitivity is $\sim 31.6455$ $\mu \mathrm{A} \mu \mathrm{M}^{-1} \mathrm{~cm}^{-2}$. To the best of our knowledge, this is the first report on the determination of Hyd using a Co-ZSM-5 (150\%-loading)/Nafion/GCE combination with the $I-V$ method for environmental approaches and it has been applied in real industrial effluents and water from the Red Sea with satisfactory results.
\end{abstract}

\section{Introduction}

Cobalt-containing ZSM-5 zeolites have drawn a great deal of attention in recent years. They have been used as catalysts for a wide range of important chemical reactions, such as oxidation of styrene and $\alpha$-pinene, ${ }^{1,2}$ direct conversion of syngas to gasoline range hydrocarbons, ${ }^{3}$ Fischer-Tropsch synthesis, ${ }^{4}$ combustion of isopropanol, ${ }^{5}$ oxidation of methane to methanol and formaldehyde $e^{6,7}$ and ammoxidation of ethane ${ }^{8}$ and ethylene. ${ }^{9}$ High activity was reported for nitrogen oxides abatement over Co-ZSM-5 catalysts. In this context, high $\mathrm{N}_{2} \mathrm{O}$ direct decomposition activity was reported over Co-ZSM-5. ${ }^{10-14}$ Earlier work by Armor and Farris ${ }^{10}$ revealed that the $\mathrm{N}_{2} \mathrm{O}$ decomposition activity of CoZSM-5 is largely unchanged as a result of its hydrothermal treatment using $2 \%$ water vapor at $750{ }^{\circ} \mathrm{C}$ compared to the dramatic loss of activity of Cu-ZSM-5 under the same treatment. Isothermal oscillations were reported during $\mathrm{N}_{2} \mathrm{O}$ direct decomposition over Co-ZSM-5. ${ }^{13}$ Co-ZSM-5 catalysts showed promising activity for the selective catalytic reduction of $\mathrm{NO}_{x}$ (SCR) with $\mathrm{CH}_{4},{ }^{14-16} \mathrm{C}_{2} \mathrm{H}_{4},{ }^{17}$ iso- $\mathrm{C}_{4} \mathrm{H}_{10},{ }^{18}$ and $\mathrm{NH}_{3} .{ }^{19}$ Under NO-SCR conditions, it was suggested that low Co loadings $(\mathrm{Co} / \mathrm{Al}<0.3)$, where isolated $\mathrm{Co}^{2+}$ ions are located in charge compensation positions, are the active sites for NO reduction, whereas the Co-oxide species are responsible for the combustion of hydrocarbons. ${ }^{\mathbf{1 4 , 1 8}}$

Center of Excellence for Advanced Materials Research (CEAMR), \& Chemistry Department, Faculty of Science, King Abdulaziz University, P.O. Box 80203, Jeddah 21589, Saudi Arabia. E-mail: mmrahman@kau.edu.sa; mmrahmanh@gmail.com; Fax: +966-12-695-2292; Tel: +966-59-642-1830

$\dagger$ Electronic supplementary information (ESI) available. See DOI: 10.1039/c7ra00952f
Various methods have been utilized for the preparation of cobaltcontaining ZSM-5 zeolites. These include hydrothermal synthesis, decomposition of metal organic complexes, incipient wetness or through ion exchange. Focusing our attention on the exchange route, this can be performed by sublimation, in a liquid solution or by using the solid state ion exchange (SSIE) method. Depending on the cobalt loading ( $\mathrm{Co} / \mathrm{Al}$ ratio) and the exchange method employed, $\mathrm{Co}^{2+}$, micro-aggregates of cobalt and oxygen, and $\mathrm{Co}-$ oxides ( $\mathrm{CoO}$ and $\mathrm{Co}_{3} \mathrm{O}_{4}$ ) in different coordination geometries were obtained., ${ }^{\mathbf{8 1 4}-18}$ The SSIE method offers the following advantages; (i) it allows the preparation of overexchanged $\mathrm{M} /$ zeolites ( $\mathrm{M} / \mathrm{Al}>0.5$ ), (ii) it is reproducible, (iii) it avoids the necessity of using large volumes of salt solutions with their accompanying waste, and (iv) it allows the exchange of multivalent cations. ${ }^{\mathbf{8 1 1 , 1 3 , 2 0}}$ Active Co-ZSM-5 catalysts for the ammoxidation of ethane and ethylene ${ }^{8}$ and $\mathrm{N}_{2} \mathrm{O}$ direct decomposition $^{11,13}$ were prepared by using the SSIE method. Based on the modification of the zeolites' dielectric constant as a result of the adsorption of a certain molecule, the zeolite-based materials are often applied as sensors with the required selectivity towards certain molecules and not to others. ${ }^{21}$ In this way, Hagena et al. ${ }^{22}$ reported the preparation of highly sensitive and selective hydrocarbon $\mathrm{Cr}_{2} \mathrm{O}_{3} / \mathrm{Na}-\mathrm{ZSM}-5$ gas sensors. Franke et al. ${ }^{23}$ developed a selective ammonia exhaust gas sensor using H-ZSM-5. Sazama et $a .^{24}$ described the application of AgH-ZSM-5 as a hightemperature sensor of water vapor. Na-ZSM-5 was used as an alkane (C1-C4) sensitive material under partial pressure changes (1-100 kPa) in the presence of $\mathrm{O}_{2} / \mathrm{CO}_{2} / \mathrm{N}_{2}$ gases. ${ }^{25}$ Using a ZSM-5based capacitor sensor, Moos et al. ${ }^{26}$ were able to detect $\mathrm{NH}_{3}$ without cross-sensitivity to $\mathrm{CO}$, hydrocarbons and $\mathrm{O}_{2}$. 
Hyd is a poisonous chemical and frequently considered a cancer-causing, toxic, hazardous, cyanogenetic and nephrotoxic substance. ${ }^{27}$ Various uses of Hyd include: pesticides, plant-growth regulators, dyes and the photographic industry, pharmaceuticals and the polymer industry, industries related to agriculture, rocket fuel, space craft fuel, and explosives. ${ }^{28}$ Symptoms of severe exposure to Hyd include: burning in eyes and nose, short-term loss of sight, fainting, vomiting, respiratory edema and unconsciousness. Liver and kidney functions may also be seriously affected by longterm exposure to Hyd. ${ }^{29}$ The central nervous system can also be affected by Hyd, sometimes leading to unconsciousness. When Hyd is absorbed through the skin, it produces caustic-like burning and also interrupts the production of blood. ${ }^{30}$ Hence, a superior analytical technique is essential for the detection and quantification of Hyd. Recently, Gang Wei et al. ${ }^{31}$ have proposed a hydrazine sensor based on a GCE coated with sulfur-doped $\gamma$-MnOOH microrods and Vellaichamy Ganesan et al. $^{32}$ have studied a guar gumbased composite coated with palladium nanoparticles for electrochemical Hyd detection, but in both approaches, linear dynamic ranges are very low and they have limitations in detecting nano-level concentrations of Hyd. Electrochemical chemi-sensors always offer a fast, powerful and cost effective method of Hyd detection and quantification. However, electrochemical oxidation of Hyd at a bare-electrode is kinetically slow and associated with high over-potential. Consequently, searching for new materials for the modification of electrodes to enhance the rate of electron transfer and reduce the over-potential of the Hyd oxidation is necessary. ${ }^{33-36}$ Several redox mediators such as metal nanoparticles, ${ }^{37,38}$ metal oxides, ${ }^{39}$ hexacyanoferrate salts, ${ }^{40}$ and organic mediators $^{41}$ have so far has been developed for this purpose. Although several Hyd detection methods, including a spectrophotometric method, ${ }^{\mathbf{4 2 , 4 3}}$ a chromatographic method, ${ }^{\mathbf{4 4}}$ titrimetric method, ${ }^{45}$ coulometry, ${ }^{46}$ electrochemistry, ${ }^{47}$ and fluorescence, ${ }^{48,49}$ have also been reported elsewhere, all these methods are either expensive or time consuming or need sophisticated instruments, and even sometimes fail to detect nano-level concentrations of Hyd. During the proficient detection of ultra-trace amounts of environmental toxicants, nanomaterials exhibit better properties than their bulk substance: for example, mechanical strength, heat tolerance, electro-catalytic property, electrical conductance, electro-magnetic property, and photo-catalytic property. ${ }^{50}$ Moreover, due to their low cost, rapid response and higher sensitivity, electrochemical sensors are often more useful than any other methods for Hyd detection.

While a literature survey showed the catalytic application of Co-ZSM-5 in many industrially important reactions, it revealed a lack of information about its sensing applications. Therefore, the purpose of this investigation is to illustrate that Co-ZSM-5 zeolites represent promising materials for selective Hyd sensing applications for environmental approaches. Here, Hyd is extremely carcinogenic and usually seriously damaging to health and environment, therefore detection by using a reliable method with Co-ZSM-5 materials using a GCE electrode is immediately required. In an investigation of Hyd, Co-ZSM-5 materials deposited as thin films on GCE are fabricated and studied in detail for chemical sensor development. An easycoating method for the construction of thin-layer Co-ZSM-5 materials within conducting binding-agents is executed for the preparation of films on GCE. In this approach, Co-ZSM-5 material fabricated films with conducting binders are utilized to target hazardous analytes using a reliable $I-V$ method under room temperature and pressure. It is confirmed that the fabricated Hyd sensor is a unique and noble research work for ultrasensitive recognition with active Co-ZSM-5 materials on GCE in a short response-time. In this work, the synthesis, electrochemical characterization, and screening for determination of Hyd using fabricated Co-ZSM-5 materials are reported.

\section{Experimental}

\subsection{Materials and methods}

$\mathrm{NH}_{4}$-ZSM-5 zeolite, with aSi/Al ratio of 11.4 (SM 27), was obtained from ALSI Penta Zeolite GmbH (Germany). The preparation of cobalt exchanged ZSM-5 by using the SSIE method has been reported in a number of previous papers., ${ }^{\mathbf{8 1 1}, 13}$ A series of cobaltexchanged ZSM-5 zeolites were prepared by heating a mechanical mixture of cobalt(II)acetate tetrahydrate (Alfa Aesar) with $\mathrm{NH}_{4}$-ZSM-5 with a target exchange level in the range $10-150 \%$ at $500{ }^{\circ} \mathrm{C}$ for $3 \mathrm{~h}$ in static air. During the heat treatment, solid-state ion exchange occurs, resulting in the formation of Co-ZSM-5 and volatile gases. Then the obtained ion-exchange products were cooled to room temperature, and placed in a bottle. The various obtained solids were referred to by abbreviations Co-ZSM- $5 \_x$, where $x$ indicates the exchange level. The laboratory grade chemical reagents, sodium hydroxide, Nafion $(5 \%$ ethanolic solution), acetone, 2-nitrophenol, 3-methoxyphenol, 4-aminophenol, 4-methoxyphenol, ethanol, hydrazine, pyridine, chloroform, dichloromethane, tetrahydrofuran, monosodium phosphate, and disodium phosphate were purchased from Sigma-Aldrich, and received no further treatment before use. Powder X-ray diffraction (XRD) patterns were recorded by using a Thermo-Scientific ARL X'TRA Powder Diffractometer using $\mathrm{Cu}$ $\mathrm{K} \alpha$ radiation $(\lambda=1.54056 \AA)$ in the $2 \theta$ range between $7^{\circ}$ and $60^{\circ}$ at room temperature. The morphology of the Co-ZSM- 5 zeolite was checked on a FESEM instrument (FESEM; JSM-7600F, Japan). Elemental analysis was performed for Co-ZSM-5 by XEDS from JEOL, Japan. The FT-IR spectra were recorded by using a Nicolet iS50 FT-IR spectrometer without $\mathrm{KBr}$ employing the Attenuated Total Reflectance (ATR) sampling accessory. Pyridine adsorption was performed in order to estimate the cobalt exchange level of the various Co-ZSM-5 samples. Detailed information about the working procedure followed is reported elsewhere. ${ }^{11,51}$ The current- $v s$.-potential $(I-V)$ technique was accomplished to detect the hydrazine in the desired range of electrical potential by a Keithley electrometer (6517A, USA) and the fabricated Co-ZSM-5 (coating with 5\% Nafion) assembly functioned as a working electrode in the desired responsive buffer system. The choice of material for various Co-doping ZSM-5 has been described in the ESI† section $(\Psi)$.

\subsection{Fabrication of Co-ZSM-5/Nafion/GCE electrode}

0.1 M phosphate buffer (PBS-solution) at $\mathrm{pH} 7.0$ was prepared by mixing of an equi-molar concentration of $0.2 \mathrm{M} \mathrm{Na}_{2} \mathrm{HPO}_{4}$ 
and $0.2 \mathrm{M} \mathrm{NaH}_{2} \mathrm{PO}_{4}$ solution in $100.0 \mathrm{~mL}$ of de-ionized water under room temperature and pressure. To fabricate the GCE, a slurry of Co-ZSM-5 was prepared with ethanol and then coated onto GCE and dried under room temperature and pressure. For the improvement of the adhesive property between GCE and CoZSM-5, a drop of 5\% ethanolic Nafion solution was added onto the fabricated working electrode. Then the electrode was placed inside an oven at a temperature of $35{ }^{\circ} \mathrm{C}$ for an hour and kept there until the conducting film was completely dried. An electrochemical cell was combined with Co-ZSM-5/Nafion/GCE and Pt-wire (dia., $1.5 \mathrm{~mm}$ ) where Co-ZSM-5/Nafion/GCE acted as the working electrode and Pt-wire was the counter electrode. The different hydrazine solutions (full concentration range: $0.01 \mathrm{nM}$ to $1.0 \mathrm{M}$ ) were prepared and incorporated in the assembled electrochemical cell as the target analyte. In the hydrazine detection process, the sensitivity (S) of the prepared working electrode with Co-ZSM-5/GCE was measured from the slope of the calibration curve (the ratio of current versus concentration). In the same way, the detection limit (DL) and linear dynamic range (LDR) were also calculated from the ratio of $3 \mathrm{~N} / \mathrm{S}$ (ratio of noise $\times 3$ vs. sensitivity). The utilized electrometer which provides a constant voltage for $I-V$ measurement is a simple two electrode system. The amount of $0.1 \mathrm{M}$ PBS-solution was kept constant in the electrochemical cell at $5.0 \mathrm{~mL}$ throughout the chemical investigation. The $I-V$ response was measured with Co-ZSM-5.

\section{Results and discussion}

\subsection{Structural and morphological characterization of Co- ZSM-5}

Fig. 1 displays the XRD patterns of the Co-ZSM- 5 samples with various Co-loadings being calcined at $500{ }^{\circ} \mathrm{C}$. In the investigated $2 \theta$ range the obtained diffracto-grams reveal the presence of the following reflections $7.92^{\circ}, 9.06^{\circ}, 13.97^{\circ}, 20.38^{\circ}, 23.28^{\circ}, 23.98^{\circ}$, $24.54^{\circ}, 30.02^{\circ}$, and $45.16^{\circ}$. These reflections can be assigned to the (101), (200), (301), (103), (501), (30 3), (313), (503), and (804) crystal planes of ZSM-5 zeolite (JCPDS file no. 79-2401). This indicates the presence of an MFI topology in the cobaltcontaining zeolite powders which remains intact during the SSIE with cobalt ions and the calcination processes. The magnified section of Fig. 1 indicates the development of one diffraction peak at $2 \theta=36.97^{\circ}$ for the samples having an exchange level $>50 \%$. This reflection could plausibly be assigned to the presence of traces of $\mathrm{Co}_{3} \mathrm{O}_{4}$ spinel oxide (JCPDS file no. 80-1545). ${ }^{52,53}$ The detection of $\mathrm{Co}_{3} \mathrm{O}_{4}$ oxide is in agreement with other data in the literature for cobalt-containing ZSM-5 zeolites prepared by different routes. ${ }^{4,5,54}$ It was shown that the low angle diffraction peaks of ZSM-5 zeolite are sensitive to the presence of impurities or species inside the zeolite channels; and, therefore, they are used to calculate the variation in crystallinity accompanying the zeolites after synthesis treatments. ${ }^{55}$ From an inspection of the low angle diffraction peaks in Fig. 1 it appears that the samples with high cobalt exchange levels show a noticeable decrease in intensity of these peaks. Therefore, the diffraction peak at $2 \theta=7.92^{\circ}$ was used to calculate the crystallinity of the calcined Co-ZSM-5 samples. In

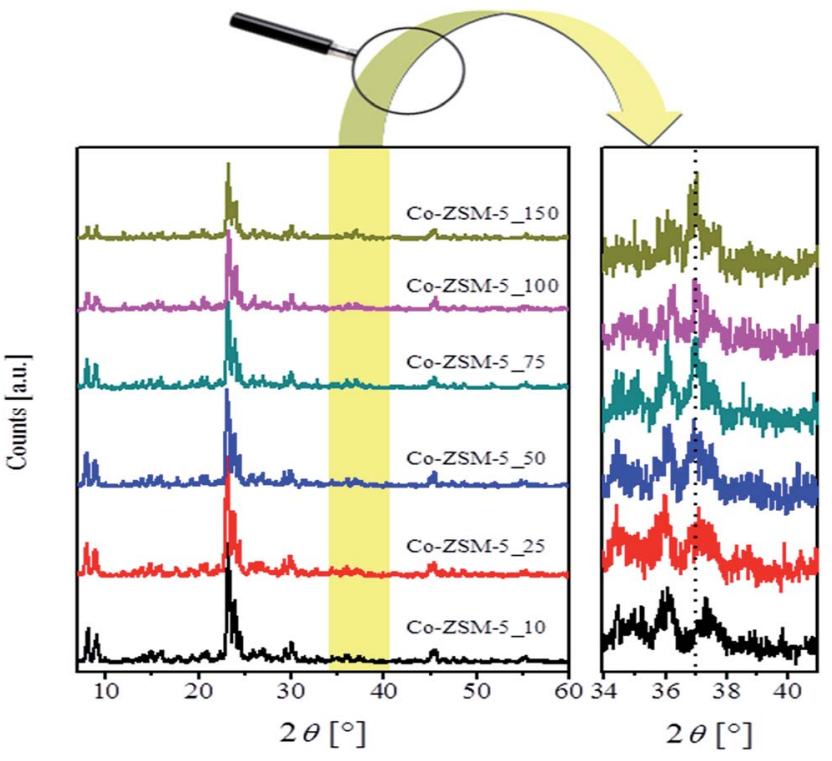

Fig. 1 XRD patterns of the various Co-ZSM- 5 zeolites prepared by the SSIE method.

comparison with the crystallinity of the H-ZSM-5, the calculated crystallinities for the Co-ZSM-5 samples were 98, 95, 93, 72, 51, and $22 \%$ for the cobalt exchange levels of $10,25,50,75,100$, and $150 \%$, respectively. This obtained crystallinity loss accompanying the increase in cobalt content could be ascribed to the possible destruction of some frameworks during the sample preparation. In agreement, El-Bahy et $a l .{ }^{54}$ reported a gradual loss in crystallinity of their Co-ZSM-5, prepared by conventional ion exchange from solution, upon increasing the cobalt $\mathrm{wt} \%$ from 2 up to $10 \%$. Higher cobalt content has led to disintegration of the ZSM-5 structure. ${ }^{56}$

The FT-IR spectra of the calcined Co-ZSM-5 samples are shown in Fig. 2. Close inspection of the spectrum of Co-ZSM-510 reveals the presence of absorption peaks at $1216 \mathrm{~cm}^{-1}, 1078$ $\mathrm{cm}^{-1}, 791 \mathrm{~cm}^{-1}, 544 \mathrm{~cm}^{-1}$ and $445 \mathrm{~cm}^{-1}$. The three absorptions located at $1216 \mathrm{~cm}^{-1}, 791 \mathrm{~cm}^{-1}$ and $445 \mathrm{~cm}^{-1}$ could be attributed to the $\mathrm{T}-\mathrm{O}$ bending, symmetric and asymmetric vibrations of the internal tetrahedron of ZSM-5, respectively. ${ }^{57-60}$ The two peaks at $1216 \mathrm{~cm}^{-1}$ and $544 \mathrm{~cm}^{-1}$ could be ascribed to the external asymmetric and the double five-ring (D5R) vibrations of $\mathrm{SiO}_{4}$ and $\mathrm{AlO}_{4}$ tetrahedra in the ZSM-5. ${ }^{\text {7-60 }}$ The same absorptions can be observed for the other Co-ZSM-5 samples. Moreover, the obtained spectra revealed the absence of the peak at around $1465 \mathrm{~cm}^{-1}$ attributable to the $\nu_{4}$ mode of vibration of the $\mathrm{NH}_{4}{ }^{+}$ion in the zeolite ${ }^{61}$ or any absorption related to the presence of cobalt acetate. ${ }^{62}$ It is known that $\mathrm{Co}_{3} \mathrm{O}_{4}$ shows two absorption peaks at $560-567 \mathrm{~cm}^{-1}$ and $656-670 \mathrm{~cm}^{-1}$ assignable to the $\nu_{1}$ and $\nu_{2}$ stretching vibrations of the Co-O bond, respectively. ${ }^{53,54}$ The position of the first $\mathrm{Co}_{3} \mathrm{O}_{4}$ peak lies in the absorption range of the D5R tetrahedral vibrations of ZSM-5. Therefore, the existence of $\mathrm{Co}_{3} \mathrm{O}_{4}$ cannot be judged from this peak. The spectra of the various Co-ZSM-5 samples indicate the emergence of a new absorption at $673 \mathrm{~cm}^{-1}$ with the increase in cobalt content. The peak could plausibly be assigned to the $\nu_{2}$ 


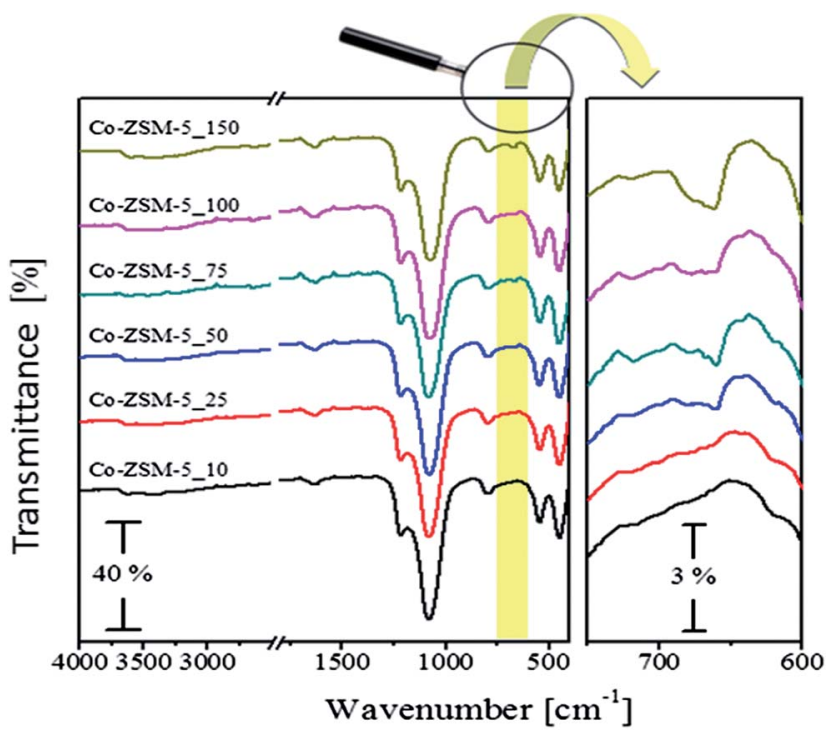

Fig. 2 FTIR spectra of the various Co-ZSM-5 samples prepared by the SSIE method.
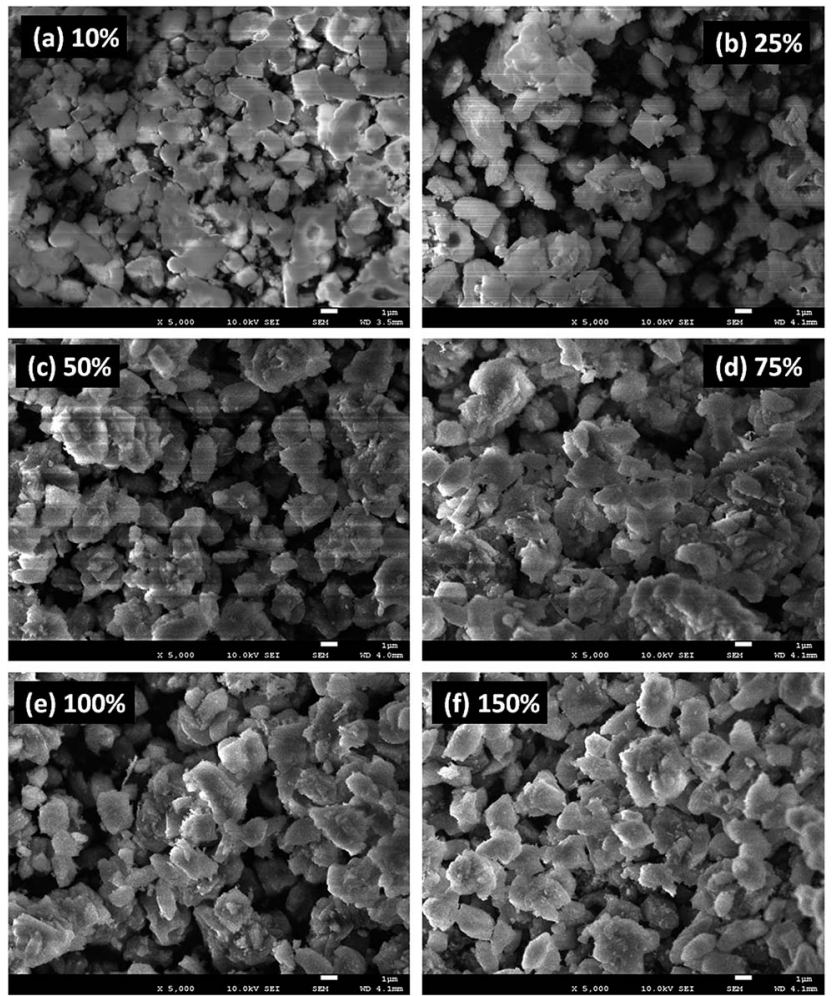

Fig. 3 Low to high magnified FE-SEM images of Co-ZSM-5 zeolites. The exchange level used for $\mathrm{NH}_{4}-$ by Co in the zeolite is (a) $10 \%$, (b) $25 \%$, (c) $50 \%$, (d) $75 \%$, (e) $100 \%$, and (f) $150 \%$.

stretching vibrations of $\mathrm{Co}_{3} \mathrm{O}_{4}$. Thus, the FT-IR results suggest the coexistence of cobalt substituted ZSM-5 and $\mathrm{Co}_{3} \mathrm{O}_{4}$ as constituents of the samples with high cobalt content, i.e. the samples with a target exchange level $\geq 50 \%$. This finding agrees well with the XRD results.
High resolution FE-SEM images of the calcined Co-ZSM-5 zeolites are exhibited in Fig. 3a-f. The FE-SEM images indicate the morphology of the prepared Co-ZSM-5 zeolites, where the exchange level of $\mathrm{NH}_{4}{ }^{+}$by $\mathrm{Co}^{2+}$ into $\mathrm{NH}_{4}-\mathrm{ZSM}-5$ is (a) $10 \%$, (b) $25 \%$, (c) $50 \%$, (d) $75 \%$, (e) $100 \%$, and (f) $150 \%$. The average diameter of Co-ZSM- 5 is calculated to be in the range of $0.6 \mu \mathrm{m}$ to $1.5 \mu \mathrm{m}$, which is close to $1.0 \mu \mathrm{m}$. It is noticeable from the FESEM images that the simple blending methodology of the prepared products results in Co-ZSM-5 zeolites, as revealed by the aggregated shape and high density of the obtained zeolites. It is also proposed that nearly all of the structure is composed of aggregated Co-ZSM-5 zeolites. ${ }^{63,64}$

$\mathrm{X}$-ray electron dispersive spectroscopy (EDS) was used to investigate the elemental composition of the prepared Co-ZSM5 materials. It is clearly shown that the prepared Co-ZSM- 5 zeolites consist of oxygen, aluminum, silicon, and cobalt elements, as presented in Fig. 4a-f. The composition of $\mathrm{O}, \mathrm{Al}, \mathrm{Si}$, and Co is presented in the selected area analysis by XEDS in the corresponding table with all exchange levels, and a comparative elemental analysis data is also included in Fig. 4a-f. From inspection of these data it appears that by increasing the loading of Co (from $10 \%$ to $150 \%$ ) into the zeolites, the weight $\%$ and atomic\% are increased gradually from $10 \%$ to a $150 \%$ loading. The obtained cobalt content values are close to the theoretical cobalt contents in the prepared Co-ZSM-5 materials, which are $0.33,0.99,1.86,2.76,3.79$, and $6.05 \mathrm{wt} \%$ for the exchange levels of $10,25,50,75,100$, and $150 \%$, respectively. No other peak related to any impurity has been detected in the XEDS (Fig. 4), which confirms that the Co-ZSM-5 zeolite products are composed of only $\mathrm{O}, \mathrm{Al}, \mathrm{Si}$, and Co elements. ${ }^{65}$

\subsection{Study of cobalt-exchange level in ZSM-5 zeolites (pyridine adsorption)}

The nature of the acid sites and the cobalt exchange level of the various Co-ZSM-5 samples were studied using pyridine adsorption. Fig. 3 shows the FT-IR spectra of adsorbed pyridine on the H-ZSM-5 and the various cobalt-containing ZSM-5 samples. The scanned wavenumber region is $1420-1470 \mathrm{~cm}^{-1}$, where the bands characteristic of both Brønsted (Bpy) and Lewis (Lpy) acids appeared. Pyridine adsorbed on H-ZSM-5 is characterized by the presence of three bands at 1448,1491 and $1547 \mathrm{~cm}^{-1}$. These absorptions could be assigned to the chemisorbed Lpy, Lpy + Bpy and Bpy, respectively. ${ }^{11,12,66,67}$ Meanwhile, the spectrum of H-ZSM5 does not show any band at $1433 \mathrm{~cm}^{-1}$, which is characteristic of physisorbed pyridine molecules on the Na-ZSM-5. ${ }^{11}$ This, in turn, indicates that the parent $\mathrm{NH}_{4}-\mathrm{ZSM}-5$ was a sodium free zeolite. The spectra obtained for the cobalt-containing zeolites reveal the presence of the three absorptions characterizing the Lpy, Lpy + Bpy and Bpy at slightly shifted positions, as shown in Table 1. Fig. 3 clearly indicates that the relative amount of Lewis acid sites increased and that of Brønsted acidity decreased upon increasing the cobalt loading. The area of Bpy with respect to that of the $\mathrm{H}$ form was used to estimate the cobalt exchange level in the various samples. The obtained values are listed in the right-hand column in Table 1. The following points could be raised from an inspection of the obtained values: (i) the obtained exchange level 

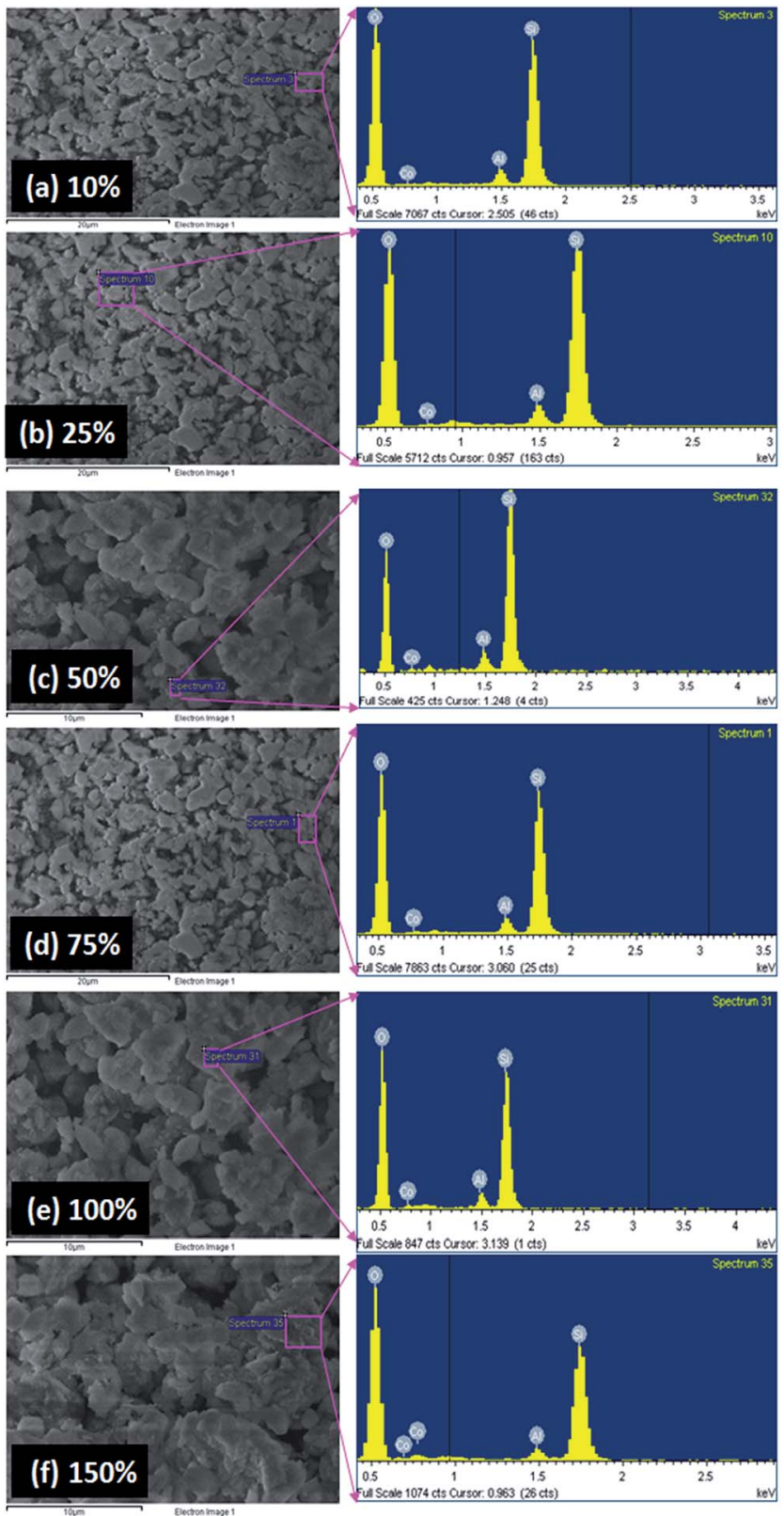

\begin{tabular}{|c|c|c|}
\hline Element & Wt $\%$ & At\% \\
\hline O K & 60.15 & $\mathbf{7 2 . 6 2}$ \\
\hline Al K & 2.99 & 2.14 \\
\hline Si K & $\mathbf{3 6 . 5 3}$ & $\mathbf{2 5 . 1 3}$ \\
\hline Co L & $\mathbf{0 . 3 3}$ & 0.11 \\
\hline Totals & \multicolumn{2}{|c|}{100.00} \\
\hline Element & Wt $\%$ & At\% \\
\hline O K & $\mathbf{5 5 . 3 4}$ & $\mathbf{6 8 . 7 0}$ \\
\hline Al K & 3.17 & 2.33 \\
\hline Si K & 40.49 & 28.63 \\
\hline Co L & 0.99 & 0.33 \\
\hline Totals & \multicolumn{2}{|c|}{100.00} \\
\hline
\end{tabular}

\begin{tabular}{|c|c|c|}
\hline Element & Wt\% & At\% \\
\hline O K & 46.15 & 60.45 \\
\hline AlK & 3.13 & 2.43 \\
\hline Si K & 48.86 & 36.46 \\
\hline Co L & 1.86 & 0.66 \\
\hline Totals & \multicolumn{2}{|c|}{100.00} \\
\hline
\end{tabular}

\begin{tabular}{|c|c|c|}
\hline Element & Wt\% & At\% \\
\hline O K & $\mathbf{5 6 . 5 2}$ & 70.18 \\
\hline AlK & 3.06 & $\mathbf{2 . 2 6}$ \\
\hline Si K & $\mathbf{3 7 . 6 6}$ & $\mathbf{2 6 . 6 3}$ \\
\hline Co L & $\mathbf{2 . 7 6}$ & $\mathbf{0 . 9 3}$ \\
\hline Totals & \multicolumn{2}{|c|}{100.00} \\
\hline
\end{tabular}

\begin{tabular}{|c|c|c|}
\hline Element & Wt\% & At\% \\
\hline O K & 56.36 & 70.32 \\
\hline Al K & 2.69 & 1.99 \\
\hline Si K & 37.16 & 26.41 \\
\hline Co L & 3.79 & 1.28 \\
\hline Totals & \multicolumn{2}{|c|}{100.00} \\
\hline
\end{tabular}

\begin{tabular}{|c|c|c|}
\hline Element & Wt\% & At\% \\
\hline O K & 60.48 & 74.45 \\
\hline Al K & 2.21 & 1.62 \\
\hline Si K & 31.25 & 21.91 \\
\hline Co L & 6.05 & 2.02 \\
\hline Totals & \multicolumn{2}{|c|}{100.00} \\
\hline
\end{tabular}

Fig. 4 Selected area of FE-SEM image of Co-ZSM-5 zeolites, corresponding Co-loading, elemental analysis of Co-ZSM-5 zeolites. The exchange level used for $\mathrm{NH}_{4}$ - by Co into the zeolites is (a) $10 \%$, (b) $25 \%$, (c) $50 \%$, (d) $75 \%$, (e) $100 \%$, and (f) $150 \%$.

Table 1 FT-IR absorption bands for adsorbed pyridine and the pyridine-estimated exchange level of cobalt

\begin{tabular}{|c|c|c|c|c|c|}
\hline Sample & Lpy $\left[\mathrm{cm}^{-1}\right]$ & Lpy + Bpy $\left[\mathrm{cm}^{-1}\right]$ & Bpy $\left[\mathrm{cm}^{-1}\right]$ & Target exchange level [\%] & $\begin{array}{l}\text { Pyridine calculated exchange } \\
\text { level }[\%]\end{array}$ \\
\hline Co-ZSM-5_10 & 1449 & 1491 & 1545 & 10 & 8 \\
\hline Co-ZSM-5_50 & 1451 & 1491 & 1544 & 50 & 46 \\
\hline Co-ZSM-5_75 & 1452 & 1492 & 1543 & 75 & 69 \\
\hline Co-ZSM-5_100 & 1452 & 1493 & 1543 & 100 & 74 \\
\hline
\end{tabular}

is lower than that of the target level for all the samples, (ii) there is a maximum exchange level that can be obtained using the SSIE method (less than $80 \%$ ), which is in agreement with a previous report using the same method to prepare various metal exchanged ZSM-5 catalysts, ${ }^{11}$ and (iii) the lower than expected obtained exchange level is in good agreement with the observed 


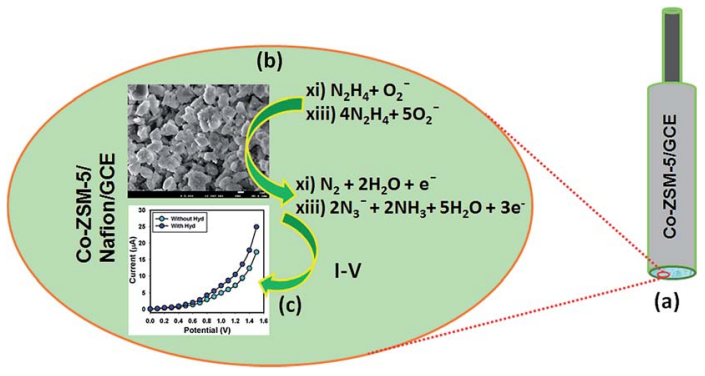

Scheme 1 Scheme representing (a) rod-shaped round-GCE electrode coated with Co-ZSM materials with conducting Nafion (5\% ethanol) coating binders, (b) proposed detection mechanism of Hyd, where Hyd is oxidized to $\mathrm{N}_{3}{ }^{-}$by releasing electrons onto Co-ZSM-5(150\%loading)/GCE, and (c) observed $I-V$ response by the Co-ZSM-5(150\%loading)/GCE. Surface area of GCE: $0.0316 \mathrm{~cm}^{2}$; method: I-V. Delay time: $1.0 \mathrm{~s}$

XRD and FT-IR detected of $\mathrm{Co}_{3} \mathrm{O}_{4}$ upon increasing the exchange level. Various mixtures were prepared for investigation of pyridine adsorption with different exchange levels and the detailed information is given in the $\mathrm{ESI} \dagger$ section $(\Phi)$.

\subsection{Detection of hydrazine with Co-ZSM-5(150\%-loading)/ Nafion/GCE materials}

The potential application of Co-ZSM-5(150\%-loading) materials assembled onto GCE as a chemical sensor (especially Hyd analyte in buffer system) has been investigated for measuring and detecting a target selected chemical. Enhancement of the
Co-ZSM-5(150\%-loading)/GCE as a chemical sensor is in its initial stage and no other reports are available. The Co-ZSM5(150\%-loading)/GCE sensors have advantages such as stability in air, non-toxicity, chemical inertness, electro-chemical activity, simplicity of assembly, ease in fabrication, and chemo-safe characteristics. As in the case of Hyd sensors, the current response in the $I-V$ method of Co-ZSM-5(150\%loading)/GCE changes considerably when aqueous Hyd analyte is adsorbed. The Co-ZSM-5(150\%-loading)/GCE is applied for the fabrication of a chemi-sensor, where hydrazine is measured as a target analyte. The fabricated-surface of a CoZSM-5(150\%-loading)/GCE sensor was prepared with conducting binders ( $5 \%$ ethanolic Nafion solution) on the GCE surface. $I-V$ signals of the Hyd chemical sensor are anticipated for thin film Co-ZSM-5(150\%-loading)/GCE as a function of current versus potential. The resultant electrical responses of target Hyd are investigated by a simple and reliable $I-V$ technique using Co-ZSM-5(150\%-loading)/GCE. The holding time of the electrometer was set at $1.0 \mathrm{~s}$. A noticeable significant magnification in the current response against applied potential is confirmed. The simple and possible reaction mechanism is generalized in Scheme 1 in the presence of Co-ZSM-5(150\%-loading)/GCE surfaces by the $I-V$ method. Hazardous Hyd in aqueous solution was detected and measured using Co-ZSM-5(150\%loading)/GCE as a chemical sensor. Its nontoxic nature, chemical stability and electrochemical activity make Co-ZSM-5(150\%loading)/GCE one of the best sensing materials for Hyd. Upon contact with Co-ZSM-5(150\%-loading)/GCE, Hyd gives
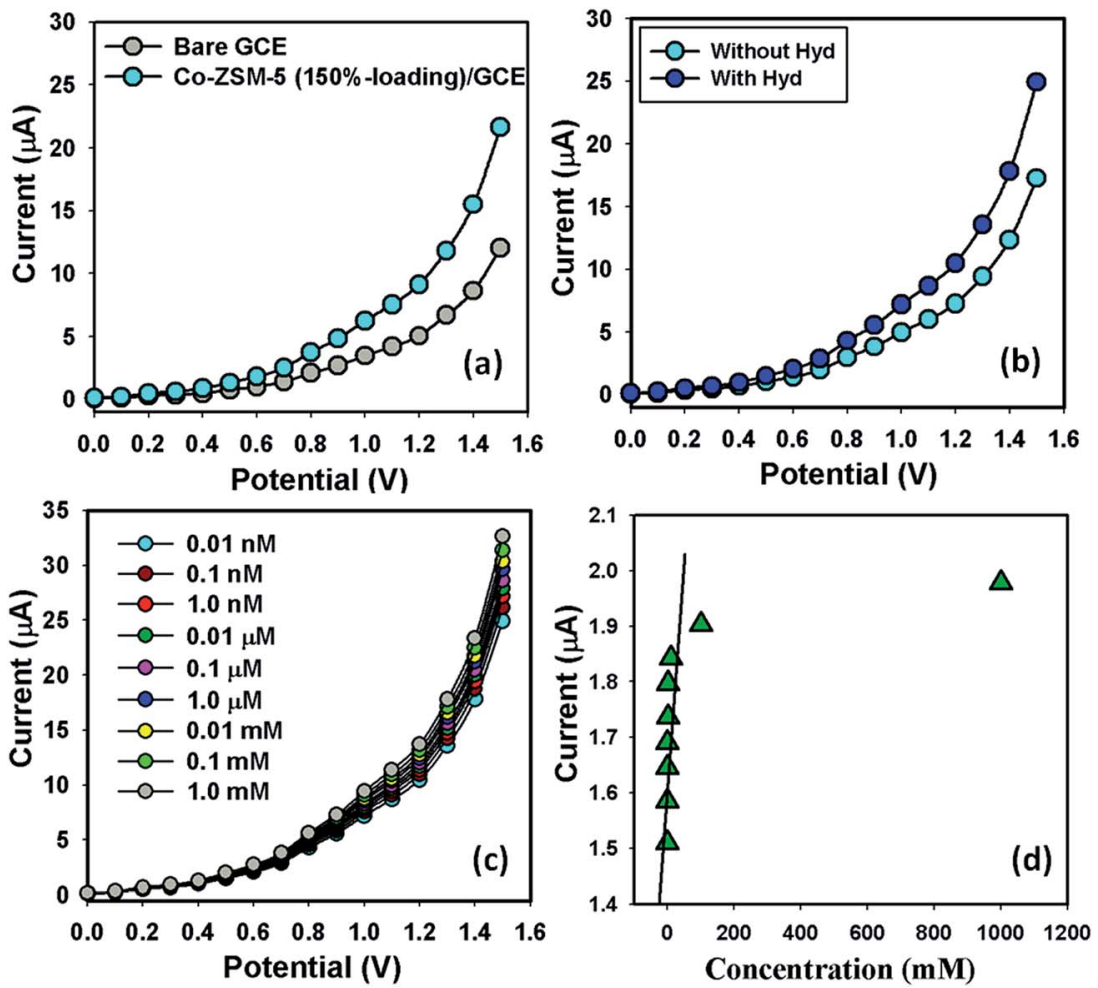

Fig. 5 (a) Uncoated and coated electrode with Co-ZSM-5 (150\%-loading) nanostructure materials, (b) absence and presence of Hyd with CoZSM-5 (150\%-loading) GCE electrode, (c) concentration variation of the Hyd with Co-ZSM-5 (150\%-loading) GCE electrode, and (d) calibration curve of the Co-ZSM-5 (150\%-loading) materials fabricated on GCE surface. 
a significant response in the simple $I-V$ method. Scheme 1(a) shows the fabricated-surface of the Co-ZSM-5(150\%-loading)/ GCE sensor prepared in 5\% ethanolic Nafion solution. The possible oxidation scheme on the Co-ZSM-5(150\%-loading)/ GCE is generalized in Scheme 1(b); where Hyd is oxidized to $\mathrm{N}_{3}{ }^{-}$, releasing free electrons on the sensor surface during $I-V$ measurements. In the presence of Hyd, electrons are also released from the adsorbed reduced oxygen species on the CoZSM-5(150\%-loading)/GCE surface, which further increases the current intensity with increasing voltage at room temperature. ${ }^{68,69}$ A practical $I-V$ response with Hyd and without Hyd on the Co-ZSM-5(150\%-loading)/GCE working electrode is given in Scheme 1(c) with a delay time of 1.0 second in the electrometer; where a higher current response to the increasing voltage is clearly demonstrated.

Fig. 5a shows that the differences in the current responses between bare and coated GCE due to the current signals were slightly affected for the coated electrode compared with the bare GCE. The target molecule, Hyd (0.01 nM to $1.0 \mathrm{mM})$, was added dropwise to the Co-ZSM-5(150\%-loading) modified electrode and the changes in current responses were recorded without (light-blue-dotted) and with (blue-dotted) analyte (Fig. 5b). Due to the presence of Co-ZSM-5(150\%-loading), a significant enhancement in current is achieved with Hyd which gives a higher surface area with better coverage in absorption and adsorption capability onto the porous zeolite surfaces for the target molecule (Hyd). The responses (current vs. voltage) of the Co-ZSM-5(150\%-loading)/GCE were recorded for the different concentrations $(0.01 \mathrm{nM}$ to $1.0 \mathrm{mM})$ of Hyd which indicates that the current of the fabricated electrode changes as a function of Hyd concentration under room temperature and pressure (Fig. 5c) and it was also reported that the current responses increased regularly from lower to higher concentration of the target analyte. For the determination of the probable analytical limit, a broad range of analyte concentrations (0.01 $\mathrm{nM}$ to 1.0 $\mathrm{mM}$ ) were measured from a lower to a higher potential ( 0 to +1.5 V). From the various concentrations of Hyd, the linear calibration and magnified calibration curve at $+0.4 \mathrm{~V}$ were plotted (Fig. 5d). The linear dynamic range $(0.01 \mathrm{nM}$ to $0.01 \mathrm{mM})$, regression coefficient $\left(r^{2}: 0.9968\right)$, detection limit (9.1 pM) and sensitivity (31.6455 $\mu \mathrm{A} \mu \mathrm{M}^{-1} \mathrm{~cm}^{-2}$; at signal to noise ratio of 3 ) were calculated from the calibration curve (Fig. 5d).

The resistance value of the Co-ZSM-5(150\%-loading) modified GCE chemical sensors could be decreased by enhancing the active surface area, which is an important criterion of the CoZSM-5(150\%-loading). ${ }^{\mathbf{7 0 , 7 1}}$ These reactions are conducted in a bulk-system/air-liquid interface/neighboring atmosphere owing to the small carrier concentration, which increased the magnitude of the resistance. The hydrazine sensitivity towards Co-ZSM-5(150\%-loading)/GCE is attributed to the higheroxygen lacking conducts to enhance the oxygen adsorption. The larger the amount of oxygen adsorbed onto the Co-ZSM-
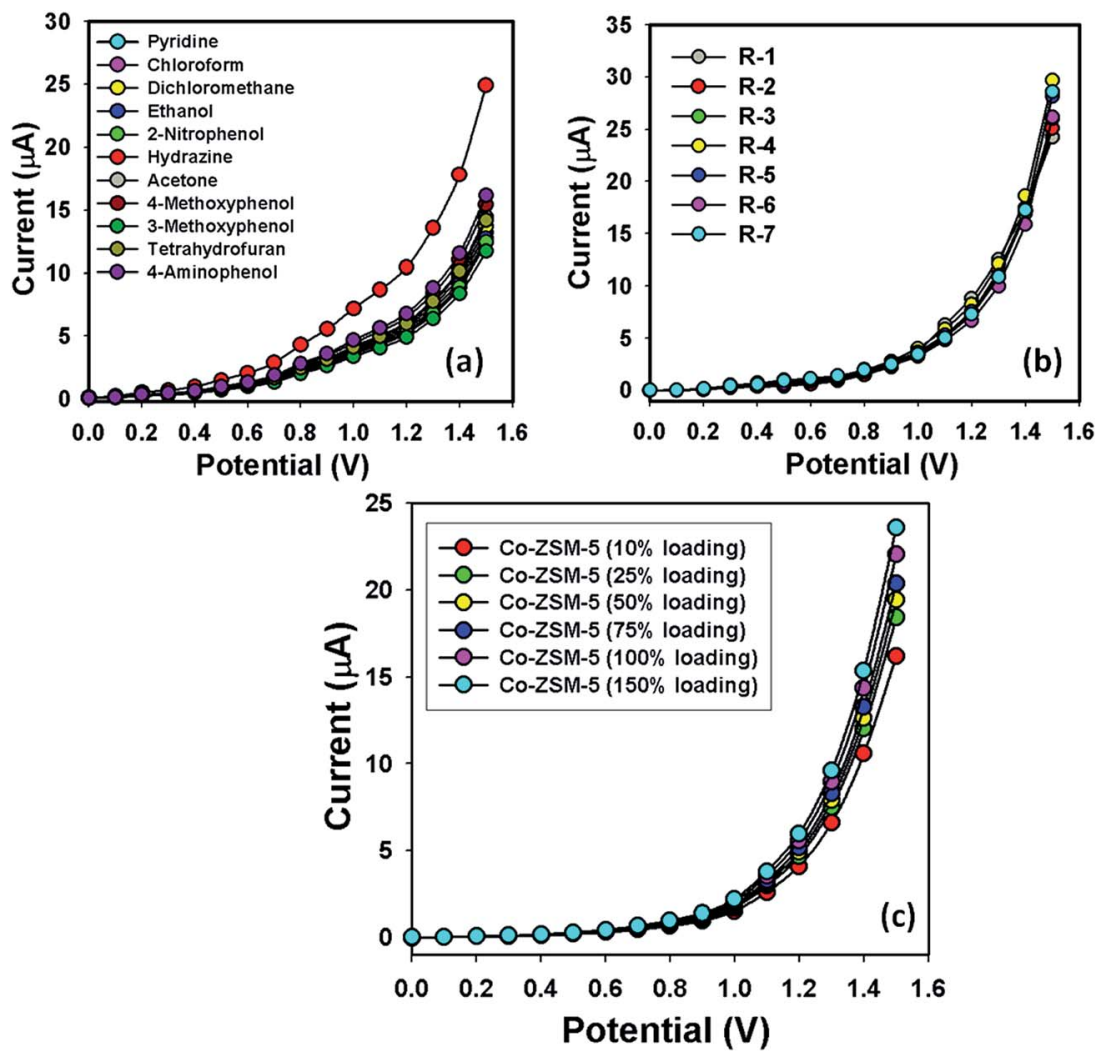

Fig. 6 Co-ZSM-5(150\%-loading)/GCE coated electrode for Hyd sensing /-V responses of (a) selectivity study $(0.1 \mu \mathrm{M} \mathrm{Hyd)}$ and (b) reproducibility study $(0.1 \mu \mathrm{M} \mathrm{Hyd})$. (c) A control experiment was performed with different percentage loadings of Co-loading into ZSM-5 (10\%, $25 \%, 50 \%, 75 \%$, $100 \%$, and $150 \%$ ) in $0.1 \mu \mathrm{M}$ Hyd. 
5 (150\%-loading)/GCE-sensor surface, the higher would be the oxidizing potentiality and the faster would be the oxidation of Hyd. The activity of Hyd would have been extremely high in contrast to other carcinogenic chemicals with the surface under room temperature and pressure. ${ }^{72,73}$

The selectivity analysis was performed with different chemicals such as pyridine, chloroform, dichloromethane, ethanol, 2-nitrophenol, hydrazine, acetone, 4-methoxyphenol, 3methoxyphenol, tetrahydrofuran, 4-aminophenol (Fig. 6a). Clear $I-V$ responses are observed in the magnified view of the selected potential area. Hyd showed maximum current responses to a Co-ZSM-5(150\%-loading)/GCE fabricated sensor and therefore it was clearly noted that the sensor was most selective towards Hyd compared with other chemicals. The $I-V$ response of the Co-ZSM-5(150\%-loading)/GCE coated electrode sensor was studied for up to 2 weeks for the determination of the reusability or reproducibility and long-term stability. It was marked that the current response was not significantly changed after washing in each experiment of the fabricated Co-ZSM5(150\%-loading)/GCE electrode substrate (Fig. 6b). The sensitivity remained similar to the initial value for up to two weeks and after that the responses of the fabricated Co-ZSM-5(150\%loading)/GCE electrode decreased gradually. Under different conditions, a series of seven successive measurements of Hyd solution $(0.1 \mu \mathrm{M})$ yielded good reproducible responses with the Co-ZSM-5(150\%-loading)/GCE (relative standard deviation, RSD: $1.8 \% ; N=7$; Run-1 to Run-7). This small \% RSD may be due to the mass variation of the coating materials, Co-ZSM-5, on the GCE working electrodes. When the same working electrode was used in different solutions of the same concentration, even under identical conditions, the current response decreased slightly. This is because after each run, the total number of active sites of the Co-ZSM-5(150\%-loading)/GCE decreases slightly. Additionally, a control experiment was also conducted in $0.1 \mu \mathrm{M}$ Hyd concentration with different Co-loadings into ZSM-5 fabricated electrodes (10\% loading, 25\% loading, 50\% loading, 75\% loading, 100\% loading, and 150\% loading) and a slight increase in current response was marked for the CoZSM-5(150\%-loading)/GCE compared with other compositions (Fig. 6c). Here, it is observed that the current response exhibited a significantly higher value for higher-Co-loading (150\%) compared to other compositions (Fig. 6c) due to the enhancement of Co-dopants into the zeolites to increase the large surface area. Based on the current responses on various compositions, the detailed Hyd sensor development is calculated for $150 \%$ Co-loading in a ZSM-5 composition in terms of all analytical parameters such as sensitivity, detection limit, linearity, reproducibility, and selectivity. The higher current response of the fabricated Co-ZSM-5(150\%-loading)/GCE could be attributed to the excellent absorption (porous surfaces in CoZSM-5(150\%-loading)/GCE) and adsorption ability, and high catalytic-decomposition activity of the conduction zeolites.

The interior resistance for the fabricated Co-ZSM-5(150\%loading)/GCE sensor decreases with the increasing electron communication characteristics that are important features of zeolites under room temperature and pressure. ${ }^{74-76}$ The adsorption of oxygen regulates a significant function in the exceptional electrochemical properties of the Co-ZSM-5(150\%loading)/GCE. The adsorption of $\mathrm{O}_{2}{ }^{-}$and/or $\mathrm{O}^{-}$ions decreases the number of electrons in the conduction band and hence increases the resistance of the Co-ZSM-5(150\%-loading)/ GCE. Dissolved $\mathrm{O}_{2}$ from the aqueous solution or surrounding atmospheric air is adsorbed on the Co-ZSM-5(150\%-loading)/ GCE surface and ionized according to eqn (i-iii).

$$
\begin{gathered}
\mathrm{O}_{2 \text { (dissolved) }} \rightarrow \mathrm{O}_{2 \text { (adsorbed) }} \\
\mathrm{O}_{2 \text { (adsorbed) }}+\mathrm{e}^{-}\left(\text {Co-ZSM-5/GCE) } \rightarrow \mathrm{O}_{2 \text { (adsorbed) }}\right. \\
\mathrm{O}_{2 \text { (adsorbed) }}^{-}+\mathrm{e}^{-}\left(\text {Co-ZSM-5/GCE) } \rightarrow 2 \mathrm{O}_{(\text {adsorbed })}\right.
\end{gathered}
$$

Oxidation of Hyd to $\mathrm{N}_{2}$ or $\mathrm{N}_{3}{ }^{-}$at the Co-ZSM-5(150\%loading)/GCE surface is the main phenomenon involved in this proposed Hyd sensor. At room temperature, reactive oxygen species $\left(\mathrm{O}_{2}{ }^{-}\right.$and $\left.\mathrm{O}^{-}\right)$are chemisorbed onto the pores of CoZSM-5(150\%-loading)/GCE, where the quantity of such adsorption is mainly dependent on the surface area of the Co-ZSM$5(150 \%$-loading)/GCE. The porous structure gives a very high surface area in the Co-ZSM-5/GCE, which is ultimately responsible for such high adsorption. Extremely high sensitivity of the Co-ZSM-5(150\%-loading)/GCE towards Hyd could be attributed to the oxidation of Hyd by adsorbed oxygen species $\left(\mathrm{O}_{2}{ }^{-}\right.$and $\mathrm{O}^{-}$). The higher the adsorption of oxygen species on the CoZSM-5(150\%-loading)/GCE, the higher will be the oxidizing power, which will oxidize Hyd quickly, resulting in the very low response time $(10 \mathrm{~s})$ of the sensor. The rate of Hyd oxidation in the Co-ZSM-5(150\%-loading)/GCE was higher than for other chemicals even under similar conditions, as shown in Scheme 1. When Hyd is oxidized by adsorbed $\mathrm{O}_{2}{ }^{-}$or $\mathrm{O}^{-}$on the Co-ZSM$5\left(150 \%\right.$-loading)/GCE surface, it converted to $\mathrm{N}_{2}$ or $\mathrm{N}_{3}{ }^{-}$, leaving electrons in the conduction band, ${ }^{77}$ as given in the following eqn (iv-vii).

$$
\begin{gathered}
\mathrm{N}_{2} \mathrm{H}_{4}+\mathrm{O}_{2}^{-} \rightarrow \mathrm{N}_{2}+2 \mathrm{H}_{2} \mathrm{O}+\mathrm{e}^{-} \\
\mathrm{N}_{2} \mathrm{H}_{4}+2 \mathrm{O}^{-} \rightarrow \mathrm{N}_{2}+2 \mathrm{H}_{2} \mathrm{O}+2 \mathrm{e}^{-} \\
4 \mathrm{~N}_{2} \mathrm{H}_{4}+5 \mathrm{O}^{-} \rightarrow 2 \mathrm{~N}_{3}^{-}+2 \mathrm{NH}_{3}+5 \mathrm{H}_{2} \mathrm{O}+3 \mathrm{e}^{-} \\
8 \mathrm{~N}_{2} \mathrm{H}_{4}+5 \mathrm{O}_{2}^{-} \rightarrow 4 \mathrm{~N}_{3}^{-}+4 \mathrm{NH}_{3}+10 \mathrm{H}_{2} \mathrm{O}+\mathrm{e}^{-}
\end{gathered}
$$

Current response in the $I-V$ method during Hyd detection largely depends on the dimensions, morphology, and nanoporosity of the Co-doped ZSM-5 zeolites (150\%-loading). When the Co-ZSM-5(150\%-loading)/GCE surface is exposed to the reducing Hyd, a surface-mediated oxidation reaction takes place. Removal of adsorbed oxygen species $\left(\mathrm{O}_{2}^{-}\right.$and $\left.\mathrm{O}^{-}\right)$ increases the number of electrons in the conduction-band and hence the surface conductance of the electrode increases. Oxidation of Hyd also provides electrons to the Co-ZSM-5(150\%loading)/GCE surface which further increases the conductance of the working electrode. ${ }^{78-80}$ Therefore, the current response intensified with the increasing potential. These supplies of electrons quickly increase the conductance of the Co-ZSM$5(150 \%$-loading)/GCE coating. Substantial loading of the Co- 
Table 2 Comparison of analytical performances of Hyd detection using various materials with conventional electrodes

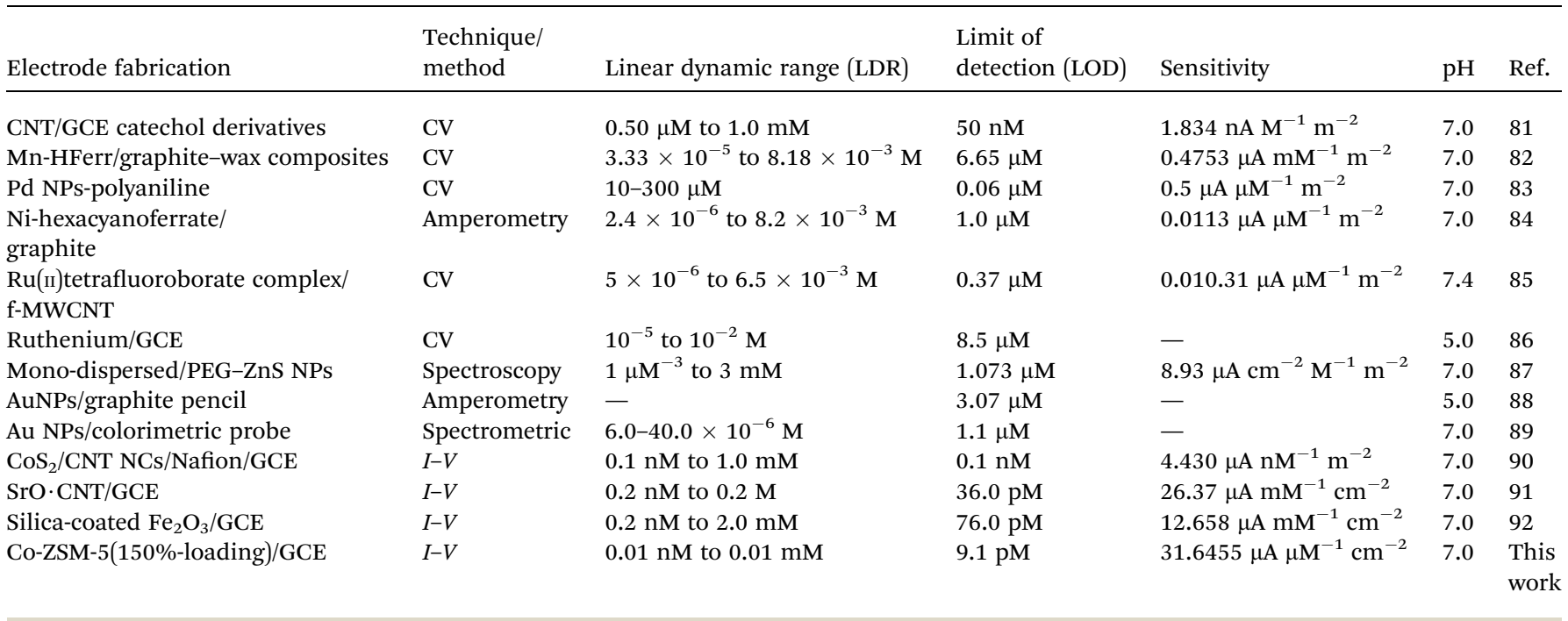

Table 3 Real sample analysis of Hyd with Co-ZSM-5(150\%-loading)/ GCE by the $I-V$ method $^{a}$

\begin{tabular}{|c|c|c|c|c|}
\hline $\begin{array}{l}\text { Real } \\
\text { sample }\end{array}$ & $\begin{array}{l}\text { Hyd } \\
\text { concentration } \\
\text { added }\end{array}$ & $\begin{array}{l}\text { Hyd } \\
\text { concentration }^{b} \\
\text { determined }^{c} \text { by } \\
\text { the Co-ZSM-5/GCE }\end{array}$ & $\begin{array}{l}\text { Recovery }{ }^{c} \\
(\%)\end{array}$ & $\begin{array}{l}\operatorname{RSD}^{d}(\%) \\
(n=3)\end{array}$ \\
\hline S1 & $0.01 \mathrm{nM}$ & $0.0102 \mathrm{nM}$ & 102.7 & 2.4 \\
\hline S1 & $0.01 \mathrm{nM}$ & $0.0101 \mathrm{nM}$ & 101.4 & 1.8 \\
\hline S1 & $0.01 \mathrm{nM}$ & $0.0098 \mathrm{nM}$ & 98.5 & 1.5 \\
\hline S2 & $0.01 \mathrm{nM}$ & $0.0103 \mathrm{nM}$ & 103.1 & 2.5 \\
\hline S2 & $0.01 \mathrm{nM}$ & $0.0101 \mathrm{nM}$ & 101.4 & 1.8 \\
\hline S2 & $0.01 \mathrm{nM}$ & $0.0099 \mathrm{nM}$ & 99.4 & 1.6 \\
\hline
\end{tabular}

${ }^{a}$ S1 and S2: real water samples collected from the industrial effluent treatment plant and Red Sea Jeddah coastline respectively, Jeddah, Saudi Arabia. ${ }^{b}$ Mean of the three repeated determinations $(\mathrm{S} / \mathrm{N}=3)$ with the Co-ZSM-5/GCE. ${ }^{c}$ Concentration of Hyd determined/ concentration of Hyd taken. ${ }^{d}$ Relative standard deviation value indicates precision among three repeated determinations.

ions into ZSM-5 with a porous/large-surface area of morphological zeolites has increased the adsorption ability of the CoZSM-5/GCE. The Co-ZSM-5(150\%-loading)/GCE sensor requires approximately $10 \mathrm{~s}$ to achieve a constant current. This excellent sensitivity and high electrochemical performance of the Co-ZSM-5(150\%-loading)/GCE are due to the porous surface that enhances the adsorption and absorption of oxygen species. The Co-ZSM-5(150\%-loading)/GCE sensor is highly sensitive towards Hyd and has a lower detection limit than other sensors already reported in Hyd detection, ${ }^{81-92}$ as given in Table 2. Having a large surface area, the Co-ZSM-5(150\%-loading)/GCE offered a positive environment during the detection and quantification of Hyd. The proposed Co-ZSM-5(150\%-loading)/ GCE sensor has also shown better reliability and stability. ${ }^{93}$ Despite these developments, there are still numerous important reservations that must be investigated more before the commercial production of this sensor.

\subsection{Real sample analysis by Co-ZSM-5/GCE electrode}

To confirm the validity of the developed sensor, the Co-ZSM-5/ GCE was used as a working electrode to quantify Hyd in industrial effluent-water (collected from the industrial effluent treatment plant, Jeddah, Saudi Arabia) and water from the Red Sea (from the Red Sea coastline, Jeddah, Saudi Arabia). For this purpose, we used the standard addition method to check the precision of the Hyd detection in aqueous samples. Fixed amounts $(\sim 25.0 \mu \mathrm{L})$ of aqueous samples of different concentrations along with the same amount of real samples were mixed and analyzed in PBS $(5.0 \mathrm{~mL})$ by the Co-ZSM-5/GCE working electrodes. Table 3 shows the results, which demonstrate that the Co-ZSM-5/GCE modified sensor showed a quantitative ( $100 \%)$ recovery of Hyd. Based on the results, therefore, it is concluded that the $I-V$ method is suitable, consistent, and appropriate in real sample analysis with the Co-ZSM-5/GCE system.

\section{Conclusions}

For the first time in this contribution, a Hyd chemical sensor was successfully fabricated based on Co-ZSM-5 (150\%-loading) zeolites immobilized on GCE with conducting Nafion binders. A simple fabrication technique was used here to build a Co-ZSM-5 (150\%-loading) electrode onto flat GCE using a conductive coating of Nafion binder. The selective and sensitive Hyd sensor was fabricated successfully based on the cobalt-containing zeolite embedded GCE as Co-ZSM-5(150\%-loading)/Nafion/ GCE. The electrochemical features of the fabricated Hyd sensor were excellent in terms of detection limit, linear dynamic range, sensitivity, repeatability, robustness, stability, and response time. The Co-ZSM-5(150\%-loading)/Nafion/GCE assembly exhibits higher sensitivity (31.6455 $\mu \mathrm{A} \mu \mathrm{M}^{-1} \mathrm{~cm}^{-2}$ ) and a lower detection limit (9.1 pM) compared to previously reported Hyd sensors. The proposed technique can be used for the development of efficient and selective sensors in the health care and environmental fields. 


\section{Acknowledgements}

The support of the Center of Excellence for Advanced Materials Research (CEAMR) at King Abdulaziz University, Jeddah, Saudi Arabia is gratefully acknowledged.

\section{References}

1 L. B. Pierella, C. Saux, S. C. Caglieri, H. R. Bertorello and P. G. Bercoff, Appl. Catal., A, 2008, 347, 55-61.

2 B. Tang, X. H. Lu, D. Zhou, J. Lei, Z. H. Niu, J. Fan and Q. H. Xia, Catal. Commun., 2012, 21, 68-71.

3 S. Sartipi, J. E. van Dijk, J. Gascon and F. Kapteijn, Appl. Catal., A, 2013, 456, 11-22.

4 M. Yao, N. Yao, Y. Shao, Q. Han, C. Ma, C. Yuan, C. Li and X. Li, Chem. Eng. J., 2014, 239, 408-415.

5 Y. Yan, L. Wang and H. Zhang, Chem. Eng. J., 2014, 255, 195204.

6 N. V. Beznis, A. N. C. van Laak, B. M. Weckhuysen and J. H. Bitter, Microporous Mesoporous Mater., 2011, 138, 176183.

7 Y. K. Krisnandi, B. A. P. Putra, M. Bahtiar, Zahara, I. Abdullah and R. F. Howe, Procedia Chem., 2015, 14, 508515.

8 M. Mhamdi, S. Khaddar-Zine and A. Ghorbel, Appl. Catal., A, 2008, 337, 39-47.

9 M. J. M. Mies, E. V. Rebrov, C. J. B. U. Schiepers, M. H. J. M. de Croon and J. C. Schouten, Chem. Eng. J., 2007, 62, 5097-5101.

10 J. N. Armor and T. S. Farris, Appl. Catal., B, 1994, 4, L11-L17. 11 B. M. Abu-Zied, W. Schwieger and A. Unger, Appl. Catal., B, 2008, 84, 277-288.

12 R. S. da Cruz, A. J. S. Mascarenhas and H. M. C. Andrade, Appl. Catal., B, 1998, 18, 223-231.

13 B. M. Abu-Zied and W. Schwieger, Appl. Catal., B, 2009, 85, 120-130.

14 P. J. Smeets, Q. Meng, S. Corthals, H. Leeman and R. A. Schoonheydt, Appl. Catal., B, 2008, 84, 505-513.

15 C. Chupin, A. C. van Veen, M. Konduru, J. Després and C. Mirodatos, J. Catal., 2006, 241, 103-114.

16 F. Lónyi, H. E. Solt, Z. Pászti and J. Valyon, Appl. Catal., B, 2014, 150-151, 218-229.

17 X.-M. Chen, X.-F. Yang, A.-M. Zhu, H.-Y. Fan, X.-K. Wang, Q. Xin, X.-R. Zhou and C. Shi, Catal. Commun., 2009, 10, 428-432.

18 X. Wang, H.-Y. Chen and W. M. H. Sachtler, Appl. Catal., B, 2000, 26, L227-L239.

19 P. N. Panahi, D. Salari, A. Niaei and S. M. Mousavi, Chin. J. Chem. Eng., 2015, 23, 1647-1654.

20 B. M. Abu-Zied, A. A. A. Farrag and A. M. Asiri, Powder Technol., 2013, 246, 643-649.

21 J. Coronas and J. Santamaria, Chem. Eng. Sci., 2004, 59, 4879-4885.

22 G. Hagena, A. Dubbea, F. Rettiga, A. Jergerb, Th. Birkhoferb, R. Müllerb, C. Plogb and R. Moos, Sens. Actuators, B, 2006, 119, 441-448.
23 M. E. Franke, U. Simon, R. Moos, A. Knezevic, R. Müller and C. Plog, Phys. Chem. Chem. Phys., 2003, 5, 5195-5198.

24 P. Sazama, H. Jirglová and J. Dědeček, Mater. Lett., 2008, 62, 4239-4241.

25 A. Dubbe and R. Moos, Sens. Actuators, B, 2008, 130, 546-550.

26 R. Moos, R. Müller, C. Plog, A. Knezevic, H. Leye, E. Irion,

T. Braum, K. J. Marquardt and K. Binder, Sens. Actuators, $B, 2002,83,181-189$.

27 M. B. Gholivand and A. Azadbakht, Electrochim. Acta, 2011, 56, 10044.

28 I. G. Casella, M. R. Guascito, A. M. Salvi and E. Desimoni, Anal. Chim. Acta, 1997, 354, 333.

29 A. Salimi, L. Miranzadeh and R. Hallaj, Talanta, 2008, 75, 147.

30 U. P. Azad and V. Ganesan, Electrochim. Acta, 2011, 56, 5766. 31 J. Ding, T. Liu, W. Xu, H. Liao, J. Li, G. Wei and Z. Su, RSC $A d v .$, 2015, 5, 80719.

32 P. K. Rastogi, V. Ganesan and S. Krishnamoorthi, Electrochim. Acta, 2014, 125, 593.

33 F. Li, B. Zhang, S. Dong and E. Wang, Electrochim. Acta, 1997, 42, 2563.

$34 \mathrm{~J} . \mathrm{Li}$ and X. Lin, Sens. Actuators, B, 2007, 126, 527.

35 S. Ivanov, U. Lange, V. Tsakova and V. M. Mirsky, Sens. Actuators, B, 2010, 150, 271.

36 H. Zhang, J. Huang, H. Hou and T. You, Electroanalysis, 2009, 21, 1869.

37 C. B. McAuley, C. E. Banks, A. O. Simm, T. G. J. Jones and R. G. Compton, Analyst, 2006, 131, 106.

38 B. Haghighi, H. Hamidi and S. Bozorgzadeh, Anal. Bioanal. Chem., 2010, 398, 1411.

39 B. Sljukic, C. E. Banks, A. Crossley and R. G. Compton, Electroanalysis, 2006, 18, 1757.

40 D. Jayasri and S. S. Narayanan, J. Hazard. Mater., 2007, 144, 348.

41 S. M. Golabi, H. R. Zare and M. Hamzehloo, Microchem. J., 2001, 69, 111.

42 A. Safavi and A. A. Ensafi, Anal. Chim. Acta, 1995, 300, 307.

43 S. Ganesh, F. Khan, M. K. Ahmed, P. Velavendan, N. K. Pandey and U. Kamachi Mudali, J. Anal. Sci., Methods Instrum., 2012, 2, 98.

44 A. D. Smolenkov, Rev. J. Chem., 2012, 2(4), 329.

45 K. R. Rao, R. Rambabu and K. R. Babu, International Journal of Innovative Research in Science, Engineering and Technology, 2013, 2(11), 6378.

46 E. C. Olson, Anal. Chem., 1960, 32, 1545.

47 L. Lauko, R. Hudec, K. Lenghartova, A. Manova, F. Cacho and E. Beinrohr, Pol. J. Environ. Stud., 2015, 24(4), 1659.

48 G. E. Collins and S. L. R. Pehrsson, Analyst, 1994, Vol. 119, 1907.

49 M. Sun, J. Guo, Q. Yang, N. Xiao and Y. Li, J. Mater. Chem. B, 2014, 2, 1846.

50 M. M. Rahman, H. B. Balkhoyora and A. M. Asiri, RSC Adv., 2016, 6, 29342.

51 S. N. Basahel, M. Mokhtar, E. H. Alsharaeh, T. T. Ali, H. A. Mahmoud and K. Narasimharao, Catalysts, 2016, 6, 57.

52 M. T. Makhlouf, B. M. Abu-Zied and T. H. Mansoure, Adv. Powder Technol., 2014, 25, 560-566. 
53 M. T. Makhlouf, B. M. Abu-Zied and T. H. Mansoure, Met. Mater. Int., 2013, 19, 489-495.

54 Z. M. El-Bahy, M. M. Mohamed, F. I. Zidan and M. S. Thabet, J. Hazard. Mat., 2008, 153, 364-371.

55 D. Dumitriu, R. Bârjega, L. Frunza, D. Macovei, T. Hu, Y. Xie, V. I. Pârvulescu and S. Kaliaguine, J. Catal., 2003, 219, 337351.

56 Y. Yan, L. Wang, H. Zhang and X. Zhang, Sep. Purif. Technol., 2017, 175, 213-221.

57 T. Xue, Y. M. Wang and M.-Y. He, Microporous Mesoporous Mater., 2012, 156, 29-35.

58 M. A. Mohamed, S. A. Halawy and M. M. Ebrahim, J. Therm. Anal., 1994, 41, 387-404.

59 H. Huang, H. Huang, Q. Feng, G. Liu, Y. Zhan, M. Wu, H. Lu, Y. Shu and D. Y. C. leung, Appl. Catal., B, 2017, 203, 870-878.

60 W. Xia, F. Wang, X. Mu, K. Chen, A. Takahashi, I. Nakamura and T. Fujitani, Catal. Commun., 2017, 91, 62-66.

61 M. O. Daramola, K. matamela and O. O. Sadare, J. Environ. Chem. Eng., 2017, 5, 54-62.

62 A. Mohamed, S. A. Halawy and M. M. Ebrahim, J. Therm. Anal., 1994, 41, 387-404.

63 X. Zhang, Q. Shen, C. He, C. Ma, J. Cheng, Z. Liu and Z. Hao, Catal. Sci. Technol., 2012, 2, 1249.

64 E. F. Iliopoulou, S. Stefanidis, K. Kalogiannis, A. C. Psarras, A. Delimitis, K. S. Triantafyllidis and A. A. Lappas, Green Chem., 2014, 16, 662.

65 Y. Ding, Y. Wang, L. Zhang, H. Zhang, C. M. Li and Y. Lei, Nanoscale, 2011, 3, 1149.

66 M. M. Mohamed and B. M. Abu-Zied, Thermochim. Acta, 2000, 359, 109-117.

67 M. Mhamdi, S. Khaddar-Zine and A. Ghorbel, Appl. Catal., A, 2009, 357, 42-50.

68 Y. Zhang, Z. Cui, L. Li, L. Guo and S. Yang, Phys. Chem. Chem. Phys., 2015, 17, 14656.

69 J. Liu, H. Chen, Z. Lin and J. M. Lin, Anal. Chem., 2010, 82, 7380.

70 M. Faisal, S. B. Khan, M. M. Rahman, A. Jamal, A. M. Asiri and M. M. Abdullah, Appl. Surf. Sci., 2011, 258, 672.

71 W. Zhou, Y. Zhou, Y. Liang, X. Feng and H. Zhou, RSC Adv., 2015, 5, 50505.

72 Y. Zhang, Z. Cui, L. Li, L. Guo and S. Yang, Phys. Chem. Chem. Phys., 2015, 17, 14656.
73 J. Liu, H. Chen, Z. Lin and J. M. Lin, Anal. Chem., 2010, 82, 7380.

74 D. Y. Wang, M. Gong, H. L. Chou, C. J. Pan, H. A. Chen, Y. Wu, M. C. Lin, M. Guan, J. Yang, C. W. Chen, Y. L. Wang, B. J. Hwang, C. C. Chen and H. Dai, J. Am. Chem. Soc., 2015, 137, 1587.

75 M. M. Rahman and A. M. Asiri, RSC Adv., 2015, 5, 63252.

76 M. M. Rahman, A. Jamal, S. B. Khan, M. Faisal and A. M. Asiri, Microchim. Acta, 2012, 178, 99.

77 M. M. Rahman, S. B. Khan, A. M. Asiri and A. G. Al-Sehemi, Electrochim. Acta, 2013, 112, 422.

78 L. M. F. Dantas, A. P. dos Reis, S. M. C. N. Tanaka, J. H. Zagal, Y. Y. Chen and A. A. Tanaka, J. Braz. Chem. Soc., 2008, 19, 720.

79 J. Wu, T. Zhou, Q. Wang and A. Umar, Sens. Actuators, B, 2016, 224, 878.

80 S. Nazir and U. Schwingenschlögl, RSC Adv., 2013, 3, 4518.

81 M. M. Rahman, A. Jamal, S. B. Khan and M. Faisal, ACS Appl. Mater. Interfaces, 2011, 3, 1346.

82 A. Salimi, L. Miranzadeh and R. Hallaj, Talanta, 2008, 75, 147.

83 D. Jayasri and S. S. Narayanan, J. Hazard. Mater., 2007, 144, 348.

84 S. Ivanov, U. Lange, V. Tsakova and V. M. Mirsky, Sens. Actuators, B, 2010, 150(271), 60-65.

85 S. J. R. Prabakar and S. S. Narayanan, J. Electroanal. Chem., 2008, 617, 111.

86 I. Tiwari, M. Gupta, P. Sinha and C. E. Banks, Mater. Res. Bull., 2014, 60, 166.

87 J. S. Pinter, K. L. Brown, P. A. DeYoung and G. F. Peaslee, Talanta, 2007, 71, 1219.

88 S. K. Mehta, Khushboo and A. Umar, Talanta, 2011, 85, 2411.

89 M. A. Aziz and A. N. Kawde, Talanta, 2013, 115, 214.

90 B. Zargar and A. Hatamie, Sens. Actuators, B, 2013, 182, 706.

91 M. M. Rahman, J. Ahmed, A. M. Asiri, I. A. Siddiquey and M. A. Hasnat, RSC Adv., 2016, 6, 90470-90479.

92 M. M. Rahman, M. M. Hussain and A. M. Asiri, RSC Adv., 2016, 6, 65338-65348.

93 H. Akhter, J. Murshed, M. A. Rashed, Y. Oshima, Y. Nagao, M. M. Rahman, A. M. Asiri, M. A. Hasnat, M. N. Uddin and I. A. Siddiquey, J. Alloys. Compounds, 2017, 698, 921-929. 